\title{
Digestão dos nutrientes e balanço de compostos nitrogenados em cabras alimentadas com quatro níveis de proteína
}

\author{
[Digestion of the nutrients and nitrogen compounds balance in goats fed with different levels of protein] \\ C.E.M. Fonseca ${ }^{1}$, R.F.D. Valadares ${ }^{2}$, S.C. Valadares Filho ${ }^{3}$, M.I. Leão ${ }^{3}$, M.I. Marcondes ${ }^{4}$ \\ ${ }^{1}$ Departamento de Produção Animal - UFRRJ \\ Rodovia BR $465-\mathrm{km} 7$ \\ 23890-000 - Seropédica, \\ ${ }^{2}$ Departamento de Veterinária - UFV - Viçosa, MG \\ ${ }^{3}$ Departamento de Zootecnia - UFV - Viçosa, MG \\ ${ }^{4}$ Aluno de Graduação - UFV - Viçosa, MG
}

\begin{abstract}
RESUMO
Avaliaram-se o consumo de alimentos, o pH e a concentração ruminal de amônia em quatro cabras, nas quais se coletou digesta de omaso via fistula ruminal para estimativa da digestão ruminal dos nutrientes. Para avaliação dos compostos nitrogenados $(\mathrm{N})$, totais urinários de $\mathrm{N}$-uréia no soro (NUS), no leite (NUL) e na urina utilizaram-se 12 cabras não fistuladas, distribuídas em três quadrados latinos $4 \times 4$. Os animais foram alimentados com rações constituídas de $50 \%$ de silagem de milho e de $50 \%$ concentrado à base da matéria seca (MS), e as dietas continham 11,$5 ; 13,5 ; 15,5$ e 17,5\% de proteína bruta na MS. Com exceção da proteína, os consumos e digestibilidades dos demais nutrientes não foram influenciados pelos níveis de $\mathrm{PB}$ nas dietas. $\mathrm{O} \mathrm{pH}$ ruminal diminuiu após o fornecimento de alimento. Com o aumento no consumo de N, ocorreram aumentos na concentração ruminal de amônia, nas concentrações de NUS e NUL, no volume urinário e no balanço de N. Conclui-se que o nível de $13,5 \%$ ou 245 gramas de PB é suficiente para cabras com produção diária de $1,6 \mathrm{~kg}$ de leite e que o método de coletas de digesta no omaso precisa ser avaliado criteriosamente para sua validação em caprinos.
\end{abstract}

Palavras-chave: caprino, compostos nitrogenados, digestão, lactação

\begin{abstract}
Feed intake, $p H$, and ruminal ammonia concentration were evaluated in four goats in which omasal digesta was collected by ruminal fistula in order to estimate the ruminal digestion of nutrients. The urinary total nitrogen compounds (N) and the concentrations of N-urea in serum (NUS), milk (NUL), and urine were evaluated in 12 goats assigned to three $4 \times 4$ Latin squares. The animals were fed rations composed of $50 \%$ of maize silage and $50 \%$ of concentrate, containing $11.5,13.5,15.5$, and $17.5 \%$ of crude protein $(C P)$ in the dry matter. With the exception of protein, the intake and total digestibility of the other nutrients were not influenced by the dietary $\mathrm{CP}$ levels. Ruminal $\mathrm{pH}$ was reduced in the postprandial period. As the $N$ intake increased, ruminal concentration of ammonia, NUS and NUL concentrations, urinary volume the $N$ balance increased. It was concluded that the level of $13.5 \%$, or 245 grams of CP, is sufficient for goats producing $1.6 \mathrm{~kg}$ per day and that the method of omasal digesta collection needs to be evaluated in more detail for its validation in goats.
\end{abstract}

Keywords:goat, digestion, lactation and nitrogen compounds

Recebido em 28 de julho de 2006

Aceito em 1 de dezembro de 2007

E-mail:elysio@ufrrj.br 


\section{INTRODUÇÃO}

O termo digestão parcial significa que a digestão total pode ser subdividida em fases de acordo com as diferentes partes do trato digestivo. Geralmente, os estudos a respeito de digestão parcial são associados com ensaio convencional de digestibilidade, procedendo-se a coletas de fezes e à coleta de digesta nas fístulas localizadas em diferentes partes do trato digestivo (Coelho da Silva e Leão, 1979).

Leão et al. (2005) compararam as estimativas da digestibilidade parcial de carboidratos totais, fibra em detergente neutro e carboidratos nãofibrosos por intermédio de coletas realizadas no abomaso ou no omaso de bovinos e concluíram que a coleta de digesta abomasal pode ser substituída pela coleta de digesta omasal, via fistula ruminal. Assim, sugeriram a utilização de animais fistulados apenas no rúmen para estudos de digestão, por constituir técnica menos invasiva que a utilização de fístulas no abomaso. $\mathrm{Na}$ literatura consultada não foram encontradas observações de digestibilidade ruminal em caprinos com uso de coletas de digesta no omaso.

A digestibilidade aparente da matéria seca (MS) pode ser influenciada pelos níveis de proteína bruta (PB) das dietas. Sahlu et al. (1993a) observaram melhor digestibilidade aparente da MS por cabras alimentadas com níveis mais elevados de PB na dieta, enquanto Badamana e Sutton (1992) não verificaram diferenças quanto às digestibilidades da MS e da matéria orgânica (MO).

Os suplementos concentrados protéicos de alta qualidade nutricional têm sido responsáveis pelo alto custo de alimentação de cabras leiteiras (Silva et al., 2006), o que leva a crer que o conhecimento da utilização de compostos nitrogenados seria interessante sob o ponto de vista produtivo. Assim, é de fundamental importância à determinação do nível adequado de PB em dietas de cabras lactantes.

A otimização do uso do nitrogênio (N) dietético requer conhecimento da partição do $\mathrm{N}$ dietético entre proteína produzida e produtos de excreção (Harmeyer e Martens, 1980). O teor de uréia na urina, no soro e no leite podem ser úteis para a avaliação do uso do $\mathrm{N}$ dietético.
O objetivo deste trabalho foi avaliar as digestibilidades total e ruminal dos nutrientes, por intermédio de coleta de digesta no omaso, o pH e a concentração ruminal de amônia, a concentração de uréia no soro e a excreção de uréia em cabras lactantes alimentadas com dietas contendo diferentes níveis de proteína bruta.

\section{MATERIAL E MÉTODOS}

Para determinação do consumo, das digestibilidades ruminal e total, da concentração de amônia e pH no rúmen foram utilizadas quatro cabras da raça Alpina, com peso médio de $45 \mathrm{~kg}$ e produção média de leite diária de $1,9 \mathrm{~kg}$, fistuladas no rúmen e confinadas em baias individuais.

As cabras foram alimentadas com quatro dietas contendo silagem de milho (47\%) e concentrado (53\%) constituído de fubá de milho, farelo de soja, uréia/sulfato de amônia e mistura mineral. As dietas foram formuladas para conter 11,5 $13,5,15,5$ e $17,5 \%$ de PB na MS total com utilização de níveis crescentes de farelo de soja em substituição ao fubá de milho (Tab. 1). As cabras foram distribuídas em um quadrado latino $4 \times 4$, sendo quatro períodos, quatro animais e quatro níveis de $\mathrm{PB}$.

A ração foi fornecida às 7 e às $16 \mathrm{~h}$, em quantidade suficiente para garantir $15 \%$ de sobras. As coletas de sobras foram efetuadas do oitavo ao $15^{\circ}$ dia de cada período experimental, sendo conservadas a $-20^{\circ} \mathrm{C}$ para posteriores análises.

Cada um dos quatro períodos teve duração de 15 dias, sendo sete dias de adaptação à dieta e oito dias de coleta de amostras. No oitavo, nono e décimo dias de cada período experimental, respectivamente, às 8,12 e $16 \mathrm{~h}$, realizaram-se coletas de amostras de digesta omasal via fistula ruminal, conforme técnica descrita por Leão (2002), para estimativa dos compostos digeridos no rúmen. Após secagem em estufa de ventilação forçada a $65^{\circ} \mathrm{C}$, durante 96 horas, as amostras foram processadas em moinho de bola e compostas proporcionalmente, com base no peso seco ao ar, por animal em cada período e armazenadas em frascos de polietileno para posteriores análises. 
Tabela 1. Proporção dos ingredientes no concentrado e teores médios de MS, MO, PB, PDR, EE, CT, FDN e CNF, segundo o nível de proteína bruta da dieta para caprinos

\begin{tabular}{|c|c|c|c|c|}
\hline \multirow{3}{*}{ Ingrediente (\%) } & \multicolumn{4}{|c|}{ Nível de PB (\%) } \\
\hline & 11,5 & 13,5 & 15,5 & 17,5 \\
\hline & \multicolumn{4}{|c|}{ Proporção dos ingredientes no concentrado ${ }^{1}$} \\
\hline Fubá de milho & 89,8 & 79,4 & 69,1 & 58,7 \\
\hline Farelo de soja & 6,0 & 16,4 & 26,7 & 37,1 \\
\hline Uréia/sulfato de amônia (9:1) & 2,0 & 2,0 & 2,0 & 2,0 \\
\hline Mistura mineral & 2,2 & 2,2 & 2,2 & 2,2 \\
\hline \multicolumn{5}{|l|}{ Composição química } \\
\hline MS (\%) & 62,1 & 61,3 & 63,4 & 64,1 \\
\hline $\mathrm{MO}^{1}$ & 95,3 & 95,3 & 94,8 & 94,7 \\
\hline $\mathrm{PB}^{1}$ & 11,3 & 13,4 & 15,5 & 17,7 \\
\hline $\mathrm{PDR}^{1,2}$ & 7,4 & 8,9 & 10,3 & 11,8 \\
\hline $\mathrm{EE}^{1}$ & 3,0 & 2,5 & 2,5 & 2,5 \\
\hline $\mathrm{CT}^{1}$ & 81,0 & 79,4 & 76,8 & 74,6 \\
\hline $\mathrm{FDN}^{1}$ & 31,5 & 31,0 & 30,5 & 30,4 \\
\hline $\mathrm{CNF}^{1}$ & 49,5 & 48,4 & 46,3 & 44,2 \\
\hline
\end{tabular}

MS: matéria seca; MO: matéria orgânica; PB: proteína bruta; PDR: proteína degradada no rúmen; EE: extrato etéreo; $\mathrm{CT}$ : carboidratos totais; FDN: fibra em detergente neutro e CNF: carboidratos não fibrosos.

$1 \%$ na $\mathrm{MS}$

${ }^{2}$ Estimada conforme dados de Valadares Filho et al. (2002).

Foram realizadas coletas de fezes do $11^{\circ}$ ao $14^{\circ}$ dia de cada período. As fezes foram reunidas de maneira a formarem amostras compostas por animal e armazenadas a $-20^{\circ} \mathrm{C}$ até a ocasião das análises laboratoriais. Para estimativa da excreção fecal e do fluxo de matéria seca no omaso, foi ministrada, diariamente às $12 \mathrm{~h}, 1,5 \mathrm{~g}$ de óxido crômico $\left(\mathrm{Cr}_{2} \mathrm{O}_{5}\right)$ via oral, para não prejudicar o bem-estar das cabras, que ingeriam o $\mathrm{Cr}_{2} \mathrm{O}_{5}$ passivamente.

Para avaliação do $\mathrm{pH}$ e da concentração de nitrogênio amoniacal ruminal, realizaram-se, no décimo quinto dia do período experimental, coletas de digesta ruminal imediatamente antes, oh e 2 e 4 horas após o fornecimento matinal de alimento. As amostras foram coletadas manualmente e filtradas por uma camada tripla de gaze, sendo imediatamente submetidas à medição de pH, por intermédio de potenciômetro. Separou-se uma alíquota de $40 \mathrm{ml}$, à qual se adicionou $1 \mathrm{ml}$ de ácido clorídrico $(1: 1)$, sendo acondicionada em frasco de polietileno, identificada e congelada a $-20^{\circ} \mathrm{C}$. Posteriormente, as amostras foram descongeladas, e a concentração de $\mathrm{N}-\mathrm{NH}_{3}$ obtida após destilação com KOH $2 \mathrm{~N}$, segundo técnica descrita por Vieira (1980).
Para avaliação do $\mathrm{N}$ total urinário e do conteúdo de uréia no soro, no leite e na urina, além das quatro cabras fistuladas, foram utilizadas 12 cabras Alpinas distribuídas em quatro quadrados latinos $4 \times 4$ e cujos procedimentos de manejo e alimentação foram os mesmos descritos para as fistuladas.

As coletas totais de urina foram realizadas no $11^{\circ}, 12^{\circ}$ e $13^{\circ}$ dia de cada período experimental. As cabras foram alojadas em baias de $1,5 \mathrm{~m}^{2}$ providas de piso ripado de madeira, sob o qual se colocava tela para separação de fezes e urina. Coletava-se a urina em galões plásticos contendo $100 \mathrm{ml}$ de $\mathrm{H}_{2} \mathrm{SO}_{4}$ a $20 \%$ providos de um funil adaptado para coleta. Ao término de cada período de 24 horas de coleta, a urina foi pesada, homogeneizada e filtrada em gaze. Alíquotas de $10 \%$ foram retiradas para constituição de amostra composta para cada animal. Para determinação do $\mathrm{N}$ total, foram congelados $50 \mathrm{ml}$ da amostra composta. Além disso, uma alíquota de $10 \mathrm{ml}$ da amostra composta foi diluída em $40 \mathrm{ml} \mathrm{de} \mathrm{H}_{2} \mathrm{SO}_{4}$ a $0,036 \mathrm{~N}$, para determinação de uréia. Ambas as amostras puras e diluídas foram acondicionadas em frascos plásticos, identificadas e armazenadas a $20^{\circ} \mathrm{C}$ para posteriores análises. 
No $13^{\circ}$ dia de cada período experimental, foram coletadas amostras de sangue de cada animal, por punção da veia jugular, aproximadamente quatro horas após o fornecimento matinal de alimento, utilizando-se tubos com acelerador de coagulação. As amostras foram imediatamente centrifugadas a 5000rpm durante 15 minutos. $\mathrm{O}$ soro resultante foi armazenado a $-20^{\circ} \mathrm{C}$ para posteriores análises de uréia.

As amostras de leite das ordenhas da manhã e da tarde, coletadas no $10^{\circ}$ dia de cada período, foram agrupadas em amostras compostas proporcionais à produção de cada ordenha e usadas para determinação do teor de $\mathrm{N}$ total. Uma alíquota de $10 \mathrm{ml}$ foi misturada com $5 \mathrm{ml}$ de ácido tricloroacético a $25 \%$ e filtrada em papel de filtro. $\mathrm{O}$ sobrenadante foi armazenado a $-20^{\circ} \mathrm{C}$ para posteriores análises de uréia. A uréia foi quantificada na urina, no soro e no leite desproteinizado, utilizando-se kit comercial ${ }^{1}$.
As amostras de alimentos, sobras e fezes foram secas a $65^{\circ} \mathrm{C}$ e moídas, e as análises de $\mathrm{MS}$, cinzas, $\mathrm{PB}$, extrato etéreo e fibra em detergente neutro dos alimentos, sobras e fezes, foram realizadas conforme Silva e Queiroz (2002).

Realizaram-se análises de variância e de regressão utilizando-se o pacote computacional SAEG (Sistema..., 1999). Para comparar as médias dos tratamentos e testar a significância dos coeficientes das regressões, foi utilizado o teste $\mathrm{t}$ de Student a $5 \%$ de probabilidade.

\section{RESULTADOS E DISCUSSÃO}

Os consumos de MS, MO, PB, extrato etéreo (EE), carboidratos totais (CT), fibra em detergente neutro (FDN), carboidratos não fibrosos (CNF) e nutrientes digestíveis totais (NDT), a produção de leite, e as equações de regressão em função do teor de PB das dietas são apresentados na Tab. 2.

Tabela 2. Médias e equações de regressão ajustadas para os consumos de MS, MO, PB, PDR, EE, CT, FDN, CNF, NDT e PL em função do nível de proteína bruta da dieta para caprinos

\begin{tabular}{|c|c|c|c|c|c|c|c|}
\hline \multirow{2}{*}{ Itens } & \multicolumn{4}{|c|}{ Nível de PB (\%) } & \multirow{2}{*}{$\mathrm{CV}$} & \multirow{2}{*}{$\mathrm{r}^{2}$} & \multirow{2}{*}{ Equação ajustada } \\
\hline & 11,5 & 13,5 & 15,5 & 17,5 & & & \\
\hline \multicolumn{8}{|c|}{ Consumo, $\mathrm{g}$} \\
\hline $\mathrm{MS}^{1}$ & 1,53 & 1,70 & 1,74 & 1,72 & 10,8 & - & $\hat{\mathrm{Y}}=1,672$ \\
\hline $\mathrm{MO}^{1}$ & 1,46 & 1,63 & 1,66 & 1,64 & 10,4 & - & $\hat{Y}=1,596$ \\
\hline $\mathrm{PB}^{2}$ & 183 & 245 & 300 & 343 & 9,3 & 0,99 & $\hat{\mathrm{Y}}=-120,84+26,8 * * \mathrm{~PB}$ \\
\hline $\mathrm{PDR}^{2}$ & 123 & 165 & 202 & 232 & 9,3 & 0,99 & $\hat{\mathrm{Y}}=-83,23+18,18 * * \mathrm{~PB}$ \\
\hline $\mathrm{EE}^{2}$ & 50,2 & 39,6 & 44,5 & 40,2 & 11,9 & - & $\hat{\mathrm{Y}}=43,6$ \\
\hline $\mathrm{CT}^{1}$ & 1,219 & 1,331 & 1,311 & 1,250 & 11,5 & - & $\hat{Y}=1,278$ \\
\hline $\mathrm{FDN}^{2}$ & 384,8 & 435,4 & 420,4 & 447,8 & 19,6 & - & $\hat{Y}=422,1$ \\
\hline $\mathrm{CNF}^{2}$ & 834,3 & 896,4 & 890,9 & 802,7 & 9,1 & - & $\hat{Y}=856,1$ \\
\hline $\mathrm{NDT}^{1}$ & 1,217 & 1,346 & 1,414 & 1,357 & 8,1 & - & $\hat{Y}=1,333$ \\
\hline \multicolumn{8}{|c|}{ Consumo, \% PV } \\
\hline MS & 3,52 & 3,86 & 3,91 & 3,94 & 13,8 & - & $\hat{\mathrm{Y}}=3,81$ \\
\hline FDN & 0,90 & 0,99 & 0,94 & 1,04 & 22,1 & - & $\hat{\mathrm{Y}}=0,966$ \\
\hline \multicolumn{8}{|c|}{ Produção de leite, $\mathrm{kg}$} \\
\hline $\mathrm{PL}^{1}$ & 1,345 & 1,359 & 1,969 & 1,637 & 26,5 & - & $\hat{\mathrm{Y}}=1,5778$ \\
\hline
\end{tabular}

MS: matéria seca; MO: matéria orgânica; PB: proteína bruta; PDR: proteína degradada no rúmen; EE: extrato etéreo; CT: carboidratos totais; FDN: fibra em detergente neutro; CNF: carboidratos não fibrosos; NDT: nutrientes digestíveis totais; PL: produção de leite.

${ }^{1} \mathrm{~kg} / \mathrm{dia} ;{ }^{2} \mathrm{~g} / \mathrm{dia}$

O consumo médio de $1,67 \mathrm{~kg} /$ dia de MS foi semelhante ao recomendado pelo AFRC (The
Nutrition..., 1997). Não foi observado efeito $(\mathrm{P}>0,05)$ dos níveis de $\mathrm{PB}$ nas dietas sobre os

${ }^{1}$ Labtest Diagnóstica - Lagoa Santa, MG 
consumos de MS e MO. Este resultado é diferente do obtido por Badamana e Sutton (1992), que observaram aumento no consumo de MS por cabras com o aumento do nível de PB da dieta. Sahlu et al. (1993b) determinaram o consumo de MS em cabras que produziam de 3,3 a 4,6kg de leite por dia, no início de lactação. Ao fornecer dietas isoenergéticas, com diferentes níveis e fontes de proteína, os autores observaram que o aumento de 13 para $17 \%$ de PB na MS ou a redução da degradabilidade da proteína bruta do farelo de soja não influenciou o consumo de MS. Ainda, a ausência de efeito da PB da dieta sobre o desempenho produtivo foi atribuída ao consumo alto de matéria seca das cabras $(4,7 \%$ do peso vivo). $\mathrm{Na}$ produção de leite, diferenças entre raças e condições ambientais podem justificar essa divergência de resultados.

Também não foi observado efeito do nível de PB na dieta sobre os consumos de EE, CT, FDN, CNF e NDT. Todas as dietas satisfizeram às necessidades dos animais em NDT. A exigência em energia para cabras nesta faixa de peso e produção, segundo o NRC (Nutrient ..., 1981), é, em média, de $1,139 \mathrm{~kg}$ de NDT/dia.
Os consumos de PB e PDR foram influenciados pela dieta, apresentando resposta linear crescente $(\mathrm{P}<0,01)$ aos níveis de $\mathrm{PB}$ da dieta. Apenas a dieta com $11,5 \%$ de $\mathrm{PB}$ não atendeu às exigências dos animais em PB, isto é, 198 gramas por dia seriam suficientes para atender às exigências propostas pelo NRC (Nutrient ..., 1981).

Os coeficientes de digestibilidade parcial e total da MS, MO, PB, EE, CT, FDN e CNF e as equações de regressão em função do teor de $\mathrm{PB}$ das dietas são apresentados na Tab. 3.

O coeficiente de digestibilidade aparente de MS é semelhante aos observados por Batista (1991) e Brun-Bellut et al. (1991), em torno de 80\%.

Os níveis de $\mathrm{PB}$ da dieta não influenciaram $(\mathrm{P}>0,05)$ os coeficientes de digestibilidade aparente total da MS, MO, EE, CT e CNF. Estes resultados assemelham-se aos obtidos por Badamana e Sutton (1992), que não observaram efeito do nível de $\mathrm{PB}$ da dieta sobre as digestibilidades da MS e da MO.

Tabela 3. Médias e equações de regressão ajustadas para as digestibilidades total e ruminal da MS, MO, $\mathrm{PB}, \mathrm{EE}, \mathrm{CT}, \mathrm{FDN}, \mathrm{CNF}$ em função do nível de proteína bruta da dieta para caprinos

\begin{tabular}{|c|c|c|c|c|c|c|c|}
\hline \multirow{2}{*}{ Itens } & \multicolumn{4}{|c|}{ Nível de PB (\%) } & \multirow{2}{*}{$\mathrm{CV}$} & \multirow{2}{*}{$\mathrm{r}$} & \multirow{2}{*}{ Equações ajustada } \\
\hline & 11,5 & 13,5 & 15,5 & 17,5 & & & \\
\hline \multicolumn{8}{|c|}{ Digestibilidade total, $\%$} \\
\hline MS & 78,4 & 80,1 & 81,3 & 79,9 & 4,1 & - & 79,9 \\
\hline $\mathrm{MO}$ & 79,8 & 81,1 & 82,5 & 81,1 & 3,7 & - & 81,12 \\
\hline PB & 74,8 & 80,8 & 83,2 & 84,7 & 3,9 & 0,91 & $\hat{\mathrm{Y}}=57,46+0,1615^{*} \mathrm{~PB}$ \\
\hline $\mathrm{EE}$ & 90,1 & 88,2 & 89,1 & 83,9 & 5,7 & - & 87,83 \\
\hline $\mathrm{CT}$ & 80,0 & 80,8 & 82,0 & 79,9 & 3,7 & - & 80,7 \\
\hline FDN & 56,7 & 61,4 & 61,0 & 60,8 & 9,9 & - & 59,96 \\
\hline $\mathrm{CNF}$ & 90,2 & 90,2 & 91,7 & 90,0 & 3,0 & - & 90,5 \\
\hline \multicolumn{8}{|c|}{ Digestibilidade ruminal, $\%$} \\
\hline $\mathrm{MS}^{1}$ & 69,4 & 62,5 & 64,2 & 59,6 & 12,4 & & $\hat{\mathrm{Y}}=63.9$ \\
\hline $\mathrm{MO}^{1}$ & 76,4 & 72,8 & 70,4 & 68,7 & 8,7 & & $\hat{\mathrm{Y}}=72,1$ \\
\hline $\mathrm{PB}^{2}$ & 23,6 & 13,0 & 19,2 & 29,2 & 50,0 & & $\hat{\mathrm{Y}}=21,3$ \\
\hline $\mathrm{EE}^{2}$ & 19,1 & 18,3 & $-18,1$ & 1,8 & 533 & & $\hat{\mathrm{Y}}=5,31$ \\
\hline $\mathrm{CT}^{1}$ & 86,9 & 85,9 & 88,3 & 61,5 & 11,5 & & $\hat{\mathrm{Y}}=85,6$ \\
\hline $\mathrm{FDN}^{1}$ & 64,8 & 73,2 & 74,3 & 74,0 & 3,7 & 0,97 & $\hat{\mathrm{Y}}=-60,23+17,11 * \mathrm{~PB}-0,54 \mathrm{~PB}^{2}$ \\
\hline $\mathrm{CNF}^{1}$ & 91,9 & 86,5 & 90,1 & 85,3 & 9,1 & & $\hat{\mathrm{Y}}=88,5$ \\
\hline
\end{tabular}

* $\mathrm{P}<0,05$ pelo teste $\mathrm{t}$

MS: matéria seca; MO: matéria orgânica; PB: proteína bruta; PDR: proteína degradada no rúmen; EE: extrato etéreo; CT: carboidratos totais; FDN: fibra em detergente neutro; CNF: carboidratos não fibrosos.

${ }^{1}$ Digestibilidade calculada em \% do total digestível.

${ }^{2}$ Digestibilidade expressa em $\%$ da quantidade que chegou ao rúmen. 
Observou-se apenas efeito dos níveis de PB sobre o coeficiente de digestibilidade aparente da proteína bruta, que apresentou comportamento linear crescente $(\mathrm{P}<0,05)$. Isso, provavelmente, resultou do maior consumo de farelo de soja, uma fonte de proteína altamente digestível, como também do efeito da diluição do $\mathrm{N}$ fecal metabólico. O aumento do consumo de PB pode influenciar positivamente a digestibilidade aparente da $\mathrm{PB}$, pois com a maior ingestão de compostos nitrogenados pode ocorrer progressiva diminuição da contribuição do $\mathrm{N}$ endógeno nos compostos nitrogenados fecais (Valadares et al., 1997).

Os coeficientes de digestibilidade parcial da MS e MO não foram influenciados pelos teores de $\mathrm{PB}$ da dieta $(\mathrm{P}>0,05)$, resultado semelhante aos obtidos por Lizieire (1989) e Batista (1991), que trabalharam com níveis de 10 a $21 \%$ de PB em dietas para cabras não gestantes e não lactantes. Esses autores não observaram diferença significativa quanto às digestibilidades ruminais da MS e da MO. Estes resultados divergem dos obtidos por Soto-Navarro et al. (2003), que observaram que a digestibilidade parcial aparente da MO aumentou linearmente com o aumento da PB dietética.

As digestibilidades ruminais da PB, EE, CT e CNF também não foram afetadas pelos teores de $\mathrm{PB}$ da dieta $(\mathrm{P}>0,05)$. $\mathrm{O}$ coeficiente de digestibilidade ruminal da FDN apresentou comportamento quadrático: $\hat{\mathrm{y}}=-60,23+$ $17,11 * \mathrm{~PB}-0,54 * \mathrm{~PB}^{2} \quad\left(\mathrm{r}^{2}=0,97, \quad \mathrm{P}<0,05\right)$. Estimou-se a digestibilidade ruminal máxima da FDN em 75,3\%, com $15,8 \%$ de PB na dieta.
As médias de $\mathrm{pH}$ ruminal em função dos níveis de $\mathrm{PB}$ nas dietas e dos tempos de coleta são apresentadas na Tab.4. Relacionando-se o $\mathrm{pH}$ do conteúdo ruminal, os níveis de $\mathrm{PB}$ na dieta e o tempo após a alimentação (T), obteve-se a seguinte regressão múltipla: $\hat{\mathrm{y}}=2,3975-$ $0,0748 * * \mathrm{~T}+0,5665 * * \mathrm{~PB}-0,0183 * \mathrm{~PB}^{2}\left(\mathrm{R}^{2}=\right.$ $82,4 \%, \quad \mathrm{P}<0,01)$. As interações não foram significativas. $\mathrm{O} \mathrm{pH}$ da digesta ruminal diminuiu com os tempos de coleta e foi influenciado de forma quadrática pelo teor de $\mathrm{PB}$ na dieta, estimando-se o $\mathrm{pH}$ máximo de 6,78 para o nível de $15,48 \%$ de PB. Este resultado diverge daqueles obtidos por Sahlu et al. (1993a), que não observaram efeito do nível de $\mathrm{PB}$ na dieta sobre o $\mathrm{pH}$ da digesta ruminal.

Segundo Morand-Fehr (1982), as cabras ruminam principalmente durante a noite. Com a ruminação, ocorre maior secreção de saliva, que possui efeito tampão sobre o conteúdo ruminal, o que pode estar relacionado com o $\mathrm{pH}$ ruminal mais alto imediatamente antes (0h) do fornecimento da alimentação matinal. Segundo Ørskov (1986), a redução do pH ruminal ocorre, principalmente, após a rápida fermentação do alimento em virtude de altas taxas de degradação, atingindo seu menor valor entre 0,5 e 4 horas após a alimentação, o que pode explicar a queda do $\mathrm{pH}$ observada nos tempos após a alimentação. Este resultado assemelha-se ao obtido por Badamana e Sutton (1992), que observaram valores mínimos de $\mathrm{pH} 3$ a 4 horas após a alimentação.

Tabela 4. Médias e equação de regressão ajustada para o pH do conteúdo ruminal de cabras lactantes de acordo com o tempo de avaliação e em função do nível de proteína bruta das dietas para caprinos

\begin{tabular}{lllll}
\hline \multirow{2}{*}{ Tempo } & \multicolumn{4}{c}{ Nível de PB nas dietas $(\%)$} \\
\cline { 2 - 5 } & 11,5 & 13,5 & 15,5 & 17,5 \\
\hline 0 & 6,53 & 6,69 & 6,68 & 6,79 \\
2 & 6,35 & 6,56 & 6,56 & 6,53 \\
4 & 6,07 & 6,58 & 6,47 & 6,38 \\
\hline
\end{tabular}

$\hat{\mathrm{y}}=2,3975-0,0748^{* *} \mathrm{~T}+0,5665^{* *} \mathrm{~PB}-0,0183 * \mathrm{~PB}^{2}$

Das 48 observações do $\mathrm{pH}$ do conteúdo ruminal, este se situou por 45 (94\%) vezes na faixa de 6,2 a 7,0. Apesar do alto teor de concentrado na dieta (53\%), o $\mathrm{pH}$ manteve-se em faixa adequada, entre 6,2 e 7,0, para a atividade dos microrganismos ruminais. $\mathrm{O} \mathrm{pH}$ pode ter sido mantido nesta faixa devido à grande capacidade de secreção de saliva pelos caprinos. A quantidade de uréia presente, $2 \%$ na $\mathrm{MS}$ dos concentrados, pode ter contribuído com a capacidade tamponante. Sahlu et al. (1993b) observaram $\mathrm{pH}$ ruminal mais elevado em cabras 
que receberam dieta com alto teor de $\mathrm{PB}$, sendo $25 \%$ dela fornecidas pela uréia. Fernandez et al. (1997) alimentaram cabras com níveis crescentes de $\mathrm{N}$ não protéico e observaran incrementos do $\mathrm{pH}$ e do teor de N-NH3 do conteúdo ruminal.

As médias de $\mathrm{N}^{-\mathrm{NH}_{3}}$ ruminal em função dos níveis de $\mathrm{PB}$ nas dietas e dos tempos de coleta são apresentadas na Tab. 5. Não foram observados efeitos do tempo e da interação tempo versus tratamento após a alimentação sobre a concentração de $\mathrm{N}_{-} \mathrm{NH}_{3}$ no rúmen, embora tenha sido observado efeito linear do conteúdo de $\mathrm{PB}$ da dieta sobre a concentração ruminal de $\mathrm{N}-\mathrm{NH}_{3}$, segundo a equação: $\hat{\mathrm{y}}=-15,2$ $+2,32 * * \mathrm{~PB}\left(\mathrm{R}^{2}=0,76, \mathrm{P}<0,001\right)$, semelhante aos resultados de vários autores (Badamana e Sutton, 1992; Sahlu et al., 1993b; Fernandez et al., 1997), que observaram teores mais elevados de $\mathrm{N}-\mathrm{NH}_{3}$ ruminal em cabras alimentadas com níveis mais altos de PB na dieta.

Tabela 5. Médias para a concentração ruminal de $\mathrm{N}-\mathrm{NH}_{3}$, em mg/dl, de acordo com o tempo de avaliação e em função do nível de $\mathrm{PB}$ na dieta para caprinos

\begin{tabular}{lcccc}
\hline \multirow{2}{*}{ Tempo } & \multicolumn{4}{c}{ Nível de PB (\%) } \\
\cline { 2 - 5 } & 11,5 & 13,5 & 15,5 & 17,5 \\
\hline 0 & $12,9( \pm 7,5)$ & $11,2( \pm 3,6)$ & $12,9( \pm 3,9)$ & $21,5( \pm 9,2)$ \\
2 & $18,9( \pm 6,9)$ & $23,2( \pm 3,6)$ & $22,3( \pm 11,6)$ & $37,5( \pm 12)$ \\
4 & $8,8( \pm 6,9)$ & $11,6( \pm 2,9)$ & $14,1( \pm 7,6)$ & $26,9( \pm 15,8)$ \\
\hline
\end{tabular}

A variação da concentração de $\mathrm{N}-\mathrm{NH}_{3}$ encontrada neste trabalho foi próxima à obtida por Fernandez et al. (1997), que observaram que o conteúdo ruminal de $\mathrm{N}_{-} \mathrm{NH}_{3}$ variou de $6,3 \mathrm{mg} / \mathrm{dl}$, em cabras alimentadas com 9,5\% de $\mathrm{PB}$, a $27,5 \mathrm{mg} / \mathrm{dl}$, em cabras alimentadas com $14 \%$ de PB na dieta. Contudo, Sahlu et al. (1993a) e Soto-Navarro et al. (2003) não observaram efeito da concentração de proteína na dieta sobre a concentração de amônia no conteúdo ruminal.

Em dietas convencionais, em que o concentrado é consumido rapidamente, ocorre variação da concentração ruminal de amônia durante o dia. Assim, o teor médio pode ultrapassar o ponto ótimo para síntese de proteína e pode haver períodos durante os quais a deficiência de $\mathrm{N}-\mathrm{NH}_{3}$ limite o crescimento microbiano. Coppock et al. (1976) observaram que a concentração de $\mathrm{N}_{-} \mathrm{NH}_{3}$ variou de 2 a $48 \mathrm{mg} / \mathrm{dl}$ com rações fornecidas duas vezes ao dia para vacas lactantes nas quais havia uréia ou amiréia. Os resultados obtidos neste trabalho assemelham-se aos desses autores.

Relacionando-se as concentrações médias de N$\mathrm{NH}_{3}$ no conteúdo ruminal e o conteúdo de uréia no soro (US), expressas em $\mathrm{mg} / \mathrm{dl}$, obteve-se a seguinte equação de regressão: $\mathrm{N}-\mathrm{NH}_{3}=-36,04$ $+0,937 * * * \mathrm{US}$, com $\mathrm{R}^{2}=80 \%$ e $\mathrm{P}<0,053$; a correlação foi alta $(\mathrm{r}=0,89)$. Valadares et al. (1997) também observaram relação positiva entre essas duas variáveis.
As médias e as equações de regressão ajustadas para as quantidades de compostos nitrogenados ingeridas, secretadas no leite, excretadas nas fezes e urina e o balanço de $\mathrm{N}$, além das concentrações de uréia na urina, $\mathrm{N}$ uréico no soro (NUS) e $\mathrm{N}$ no leite (NUL) e a relação $\mathrm{N}$ uréico/N total (NU/NT) são apresentadas na Tab. 6.

$\mathrm{O}$ consumo de $\mathrm{N}$ (g/d) aumentou com o incremento do teor de $\mathrm{PB}$ da dieta. À medida que houve aumento no consumo de compostos nitrogenados, a concentração de $\mathrm{N}$-uréico no soro (NUS) também apresentou comportamento linear crescente. Este resultado é semelhante ao obtido por outros pesquisadores, que observaram relação positiva entre o consumo de $\mathrm{PB}$ e o Nuréico plasmático (NUP) em caprinos. BrunBellut et al. (1991) observaram concentração de $21,9 \mathrm{mg} / \mathrm{dl}$ de $\mathrm{N}$ uréico no plasma de cabras leiteiras alimentadas com $13,3 \%$ de PB na dieta e Sahlu et al. (1993a) encontraram valores de 8,3, 22,0 e $33,3 \mathrm{mg} / \mathrm{dl}$ de NUP em cabras alimentadas, respectivamente com 9,15 e $21 \%$ de PB na dieta.

A elevação do consumo de $\mathrm{N}$ resultou no aumento da quantidade de $\mathrm{N}$ secretado no leite. A concentração, expressa em $\mathrm{mg} / \mathrm{dl}$, de N-uréia no leite (NUL), relacionou-se positivamente com o conteúdo de $\mathrm{N}$-uréia no soro, de acordo com a equação: $\mathrm{NUS}=5,1524+0,9437 \mathrm{NUL}$, com $\mathrm{R}^{2}=$ $45 \%$ e $\mathrm{P}<0,0001$. 
Tabela 6. Médias e determinação $\left(\mathrm{r}^{2}\right)$ e equações de regressão ajustadas para as quantidades de compostos nitrogenados $(\mathrm{N})$ ingeridos, excretadas nas fezes e urina e secretados no leite, balanço de $\mathrm{N}(\mathrm{BN})$, excreção urinária de uréia (UU) e concentrações de N uréico no soro (NUS) e no leite (NUL) e relação N uréico/N total na urina (NU/NT) em função do nível de proteína bruta (PB) na dieta para caprinos

\begin{tabular}{|c|c|c|c|c|c|c|c|}
\hline \multirow{2}{*}{ Itens } & \multicolumn{4}{|c|}{ Nível de PB (\%) } & \multirow[b]{2}{*}{$\mathrm{CV}$} & \multirow[b]{2}{*}{$r^{2}$} & \multirow{2}{*}{ Equações ajustadas } \\
\hline & 11,5 & 13,5 & 15,5 & 17,5 & & & \\
\hline $\mathrm{N}$ ingerido g/dia & 38,6 & 46,4 & 58,9 & 71,6 & 9,6 & 0,99 & $\hat{\mathrm{Y}}=-27,055+5,58^{* *} \mathrm{~PB}$ \\
\hline $\mathrm{N}$ fecal g/dia & 9,1 & 9,8 & 10,7 & 11,7 & 17,6 & 0,99 & $\hat{\mathrm{Y}}=3,973+0,4387^{* *} \mathrm{~PB}$ \\
\hline $\mathrm{N}$ urina $\mathrm{g} /$ dia & 6,8 & 8,7 & 13,4 & 16,7 & 22,0 & 0,98 & $\hat{\mathrm{Y}}=--13,484+1,7177 * * \mathrm{~PB}$ \\
\hline $\mathrm{N}$ leite $\mathrm{g} /$ dia & 12,2 & 12,5 & 12,6 & 14,3 & 16,4 & 0,75 & $\hat{\mathrm{Y}}=8,244+0,3207 * \mathrm{~PB}$ \\
\hline $\mathrm{BN} g$ & 10,5 & 15,4 & 22,2 & 28,9 & 23,7 & 0,99 & $\hat{\mathrm{Y}}=-25,788+3,1036^{* *} \mathrm{~PB}$ \\
\hline UU mg $/ \mathrm{kg}^{0,75}$ & 122 & 276 & 424 & 544 & 27,2 & 0,99 & $\hat{\mathrm{Y}}=-0,539+61,802 * * \mathrm{~PB}$ \\
\hline NUS mg/dl & 24,4 & 24,6 & 28,2 & 31,3 & 11,0 & 0,91 & $\hat{\mathrm{Y}}=9,555+1,2137 * * \mathrm{~PB}$ \\
\hline NUL $\mathrm{mg} / \mathrm{kg}^{0,75}$ & 20,2 & 22,4 & 24,7 & 25,9 & 8,8 & 0,99 & $\hat{\mathrm{Y}}=9,23+0,9712 * * \mathrm{~PB}$ \\
\hline NU/NT \% & 62,9 & 71,2 & 73,8 & 74,8 & 17,9 & 0,83 & $\hat{\mathrm{Y}}=43,098+1,90247 * \mathrm{~PB}$ \\
\hline
\end{tabular}

*P $<0,05 ; * * \mathrm{p}<0,01$ pelo teste $\mathrm{t}$

Segundo Morand-Fehr e Sauvant (1980), o excesso de proteína na dieta não melhora a porcentagem de proteína no leite de cabra, e sim aumenta o conteúdo de nitrogênio não proteico $\mathrm{e}$ de uréia no leite. Da mesma forma, observou-se aumento linear na excreção de N-total e de uréia na urina em função do aumento da PB dietética (Tab. 5), o que pode estar relacionado ao aumento da ingestão de PB.

A relação $\mathrm{N}$-uréia: $\mathrm{N}$ total na urina também foi influenciada positivamente pelo teor de PB na dieta, demonstrando que, à medida que se aumenta o teor de PB da dieta, maior é o percentual do $\mathrm{N}$ total excretado na forma de uréia. Resultados semelhantes foram obtidos por Valadares et al. (1997), que trabalharam com níveis crescentes de $\mathrm{PB}$ na dieta de bovinos e observaram que a relação $\mathrm{N}$-uréia: $\mathrm{N}$ total variou de $29,4 \%$ no tratamento com $7 \%$ de PB na dieta a $87,6 \%$ no tratamento com $14,5 \%$ de $\mathrm{PB}$ na dieta.

Relacionando-se a excreção de N-uréia na urina (NUU) com a concentração de N-uréia no soro (NUS), obteve-se a seguinte regressão: NUU = $9,67+0,657$ NUS, com $\mathrm{R}^{2}=34 \%$ e $\mathrm{P}<0,0001$. Isso mostra que existe relação positiva entre o $\mathrm{N}$ excretado em forma de uréia na urina e a concentração de uréia no soro.

Apesar da excreção crescente de compostos nitrogenados no leite, na urina e nas fezes, o balanço de nitrogênio apresentou comportamento linear crescente em função do conteúdo de PB da dieta.

\section{CONCLUSÕES}

O nível de $13,5 \%$ ou 245 gramas de $\mathrm{PB}$ é suficiente para atender às exigências de cabras que consomem $1,6 \mathrm{~kg}$ ou $3,8 \%$ do peso vivo em MS e produção diária de $1,6 \mathrm{~kg}$ de leite. A técnica de coletas de digesta no omaso precisa ser avaliada criteriosamente para que possa ser validada para ensaios de digestão parcial em caprinos.

\section{AGRADECIMENTOS}

À FAPEMIG pela concessão de Bolsa de Iniciação Científica a Marcos Inácio Marcondes. Ao CNPq e a FAPEMIG pelo apoio financeiro e a CAPES/PICDT pela concessão de Bolsa de Doutorado a Carlos Elysio Moreira da Fonseca. A Marlos Oliveira Porto e Marcelo Teixeira Rodrigues pela colaboração a este trabalho.

\section{REFERÊNCIAS BIBLIOGRÁFICAS}

BADAMANA, M.S.; SUTTON, J.D. Hay intake, milk production, and rumen fermentation in British Saanen goats given concentrates varying widely in protein concentration. Anim. Prod., v.54, p.395403, 1992.

BATISTA, A.M.V. Degradabilidade da proteina bruta da ração e digestão em cabras não-gestantes e não-lactantes e no terço final da gestação. 1991. 96f. Dissertação (Mestrado) - Universidade Federal de Viçosa, Viçosa, MG. 
BRUN-BELLUT, J.; KELLY, J. M.; MATHISON, G.W. et al. Effect of rumen degradable protein and lactation on nitrogen metabolism in dairy goats. Can. J. Anim. Sci., v.71, p.1111-1124, 1991.

COELHO DA SILVA, J.F., LEÃO, M.I. Fundamentos de nutrição dos ruminantes. Piracicaba: Livroceres, 1979. 384p.

COPPOCK, C.E.; PEPLOWSKI, M.A.; LAKE, G.B. Effect of urea form and method of feeding on rumen ammonia concentration. J. Dairy Sci., v.59, p.1153-1156, 1976.

FERNANDEZ, J.M.; SAHLU, T.; LU, C.D. et al. Production and metabolic aspects of nonprotein nitrogen incorporation in lactation rations of dairy goats. Small Rum. Res., v.26, p.105-117, 1997.

HARMEYER, J.; MARTENS, H. Aspects of urea metabolism in ruminants with reference to the goat. J. Dairy Sci., v.63. p.1707-1728, 1980.

LEÃO, M.I. Metodologia de coletas de digestas omasal e abomasal em novilhos submetidos a três niveis de ingestão: consumo digestibilidade $e$ produção microbiana. 2002. 57f. Tese (Doutorado) - Escola de Veterinária, Universidade Federal de Minas Gerais, Belo Horizonte.

LEÃO, M.I.; VALADARES FILHO, S.C.; RENNÓ, L.N. et al. Consumos e digestibilidades totais e parciais de carboidratos totais, fibra em detergente neutro e carboidratos não fibrosos em novilhos submetidos a três níveis de ingestão e duas metodologias de coletas de digestas abomasal e omasal. Rev. Bras. Zootec., v.34, p.670-678, 2005.

LIZIEIRE, R.S. Efeitos de níveis crescentes de proteína degradada no rúmen sobre o consumo, digestibilidade e alguns parâmetros da fermentação ruminal em cabras. 1989. 74f. Dissertação (Mestrado) - Universidade Federal de Viçosa, Viçosa, MG.

MORAND-FEHR, P. Nutrition and feeding of goats: application to temperate climatic conditions. In: C. GALL (Ed). Goat production. New York: Academic Press, 1982. p.193-232.

MORAND-FEHR, P.; SAUVANT, D. Composition and yield of goat milk as affected by nutritional manipulation. J. Dairy Sci., v.63, p.1671-1680, 1980
NUTRIENT requirements of goats: angora, dairy, and meat goats in temperate tropical countries. Washington: NRC, 1981.91p.

ØRSKOV, E.R. Starch digestion and utilization in ruminants. J. Anim. Sci., v.63, p.1624-1633, 1986.

SAHLU, T.; HART, S.P.; FERNANDEZ, J.M. Nitrogen metabolism and blood metabolites in three goat breeds fed increasing amounts of protein. Small Rum. Res., v.10, p.281-292, 1993a.

SAHLU, T.; FERNANDEZ J.M.; JIA, Z.H. et al. Effect of source and amount of protein on milk production in dairy goats. J. Dairy Sci., v.76, p.2701-2710, 1993b.

SILVA, J.D.; QUEIROZ, A.C. Análise de alimentos: métodos químicos e biológicos. 2.ed. Viçosa: UFV, 2002. 156p.

SILVA, H.G.O.; PIRES, A.J.V.; SILVA, F.F. et al. Características físico-químicas e custo do leite de cabras alimentadas com farelo de cacau ou torta de dendê. Arq. Bras. Med. Vet. Zootec., v.58, p.116123, 2006.

SISTEMA de análises estatísticas. SAEG. Versão 8.0. Viçosa: UFV. 1999. 141p.

SOTO-NAVARRO, S.A.; GOETTSCH, A.L.; SAHLU, T. et al. Effects of ruminally degraded nitrogen source and level in a high concentrate diet on site of digestion in yearling Boer $\mathrm{x}$ Spanish wether goats. Small Rum. Res., v.50, p.117-128, 2003

THE NUTRITION of goats. Nutr. Rev. Abst. (Series B), v.67, p.826-844, 1997.

VALADARES FILHO, S.C.; ROCHA Jr., V.R.; CAPPELLE,E.R. Tabelas brasileiras de composição de alimentos para bovinos. Viçosa: UFV, 2002. 297p.

VALADARES, R.F.D.; GONÇALVES, L.C.; RODRIGUEZ, N.M. et al. Níveis de proteína em dietas de bovinos. Rev. Bras. Zootec., v.26, p.12701278, 1997.

VIEIRA, P.F. Efeito do formaldeido na proteção de proteinas e lipídeos em rações para ruminantes. 1980. 98f. Tese (Doutorado) - Universidade Federal de Viçosa, Viçosa, MG. 